\title{
Work in Progress: 'I'm Not Your Standard Student": Examining the Ratio- nales for Studying MDE or IDES Programs through Usability Interviews
}

\section{Ms. Brianna Shani Benedict, Purdue University, West Lafayette}

Brianna Benedict is a Graduate Research Assistant in the School of Engineering Education at Purdue University. She completed her Bachelor's and Master's of Science in Industrial and Systems Engineering at North Carolina Agricultural \& Technical State University. Her research interest focuses on interdisciplinary students' identity development, belongingness in engineering, and recognition.

\section{Dr. Robin Adams, Purdue University, West Lafayette}

Robin S. Adams is an Associate Professor in the School of Engineering Education at Purdue University and holds a PhD in Education, an MS in Materials Science and Engineering, and a BS in Mechanical Engineering. She researches cross-disciplinarity ways of thinking, acting and being; design learning; and engineering education transformation. 


\title{
Work-In-Progress: 'I'm Not Your Standard Student": Examining the Rationales for Pursuing an Interdisciplinary Engineering Education
}

\begin{abstract}
This Work-in-Progress paper in the Multidisciplinary Engineering Division begins to explore how undergraduate students use program websites to identify and select an engineering education program that supports their diverse interests. Traditional disciplinary engineering curricula are often perceived as limiting for some students. However, multidisciplinary engineering or interdisciplinary engineering education programs provide opportunities for students to pursue engineering as a career that aligns with their interest, career goals, and a space to establish a sense of belonging. Prior studies have broadly examined what influences students to select engineering as a major; however, little work has explored what influences students in their decision making to transition to an interdisciplinary engineering education program. In this work-in-progress paper, we describe our preliminary findings from a usability study using the program websites to elicit responses about what influences students' identification with multidisciplinary engineering or interdisciplinary engineering studies programs. These user experiences begin to provide insight into how students use websites to identify multidisciplinary engineering or interdisciplinary engineering studies program as an academic home, student rationale for changing their degree, instead of staying in a traditional engineering program, and suggestions on how program websites can be improved to support prospective students with their decision to select an interdisciplinary engineering education program.
\end{abstract}

\section{Introduction}

The need for interdisciplinarity within engineering education has been discussed regarding the necessity for engineers who can work on multidisciplinary teams, produce engineering solutions that balance multiple perspectives, synthesize knowledge to solve complex problems, and communicate their ideas to diverse audiences [1]-[2]. More importantly, the Engineer of 2020 report described the importance for engineers who can be open to "nonengineering disciplines such as science, social science, and business [2, p. 50]." This highlights the need to investigate how students become aware of interdisciplinary engineering education as an option, as well as to understand the experiences of students who do not identify with the curriculum structures of traditional engineering disciplines.

Prior engineering education work has investigated how students feel marginalized according to their social identity [3] or sense-making identities [4] in the culture of engineering. We understand the reasons why students choose engineering as a career [5], disciplinary choice [6]-[7], and student migration within engineering [8]. However, little work has investigated the experiences of students who recognize a lack of fit as a first-year engineering student or leave a traditional engineering program and transfer to a program with essence of interdisciplinarity. This work highlights the experiences of seven undergraduate engineering students who describe their rationale for pursuing a unique, self-designed engineering education. 


\section{Interdisciplinary Programs}

The landscape of interdisciplinary programs has been explored from a general level of interdisciplinary studies. Knight and colleagues (2013) identified variations of interdisciplinary programs and characterized typologies of interdisciplinarity [9]. The programs included in their analysis were not broadly inclusive of engineering programs with an interdisciplinary component. Although their work discussed the importance of interdisciplinarity from an engineering education perspective, it was unclear how the programs in their study support undergraduate engineering students or offer a student level perspective regarding the value of an interdisciplinary engineering education. It is important to make meaning of why students are attracted to interdisciplinary-like programs, in addition to the national call for citizens that can solve complex problems. Our work begins to unpack how a multidisciplinary engineering or interdisciplinary engineering education enable students to define their own identity as an engineer with program structures that empower students to take ownership of their education.

\section{Identity and Agency in Engineering Education}

Identity formation is a critical aspect of whether students' see themselves as someone who can become a "science person" or engineer in relation to their performance/competence beliefs, interest, and recognition by the community as a member of the perceived identity [10]-[11]. Earlier work identified how recognition is a critical aspect of identity formation [11]. Godwin and her colleagues found that performance/ competence beliefs alone will not suffice in identity formation; instead engineering students should have experiences that are mediated with interest and recognition [11]. Additional identity research shows how instead of "asking students to conform to the norms of engineering as 'what counts' and 'who belongs,' we need to identify ways to recognize the benefits of various types of students who can succeed in engineering [12, p. 13]." This work highlights the need to provide avenues for students to author their identities as engineers which would include crossing boundaries and stop privileging "engineering and science disciplines and knowledge over social sciences and humanities (by and large: economics being an obvious exception) [13, p. 255]." This works speaks to an education that is inclusive of students' interests, as well as not limiting students by "disciplining" with certain ways of knowing, thinking, and being centralized in engineering.

\section{Research Questions}

This work describes a pilot study to understand the rationales for a student's decision to pursue an interdisciplinary engineering education. We used qualitative research methods to answer the following research questions:

1. What information on program websites is essential for students to make decisions about their undergraduate education?

2. Why are students interested in pursuing an interdisciplinary program, as opposed to traditional disciplinary engineering programs? 
Our findings are not meant to provide a comprehensive understanding of student experiences in interdisciplinary programs or conduct a robust evaluation of the website. Instead, we aim to provide preliminary insights into what shaped the student's decision to pursue an interdisciplinary engineering education.

\section{Methods}

\section{Study Context}

A school at a large midwestern university manages three essential undergraduate programs in the college of engineering: first-year engineering program, multidisciplinary engineering program (MDE), and interdisciplinary engineering studies program (IDES). All engineering students must complete first-year engineering requirements before transitioning to their preferred academic major. Students that are interested in an interdisciplinary engineering education apply to this school. One leadership and advising office manages the MDE and IDES programs; however, the programs are administered as two separate entities. Students who pursue an interdisciplinary engineering studies education (IDES) do not plan to practice engineering, while the multidisciplinary engineering program (MDE) is ABET accredited and provides students with an education that supports an engineering career by combining multiple disciplines to solve their problems of interests.

\section{Participants}

We used purposeful sampling to recruit participants for this pilot study. To be broadly eligible for participation, students had to be currently enrolled in either the interdisciplinary engineering studies (IDES) $(n=1)$ or multidisciplinary engineering (MDE) $(n=6)$ program. To capture variations in students' rationales we purposefully recruited a heterogeneous sample of students with diverse interests and concentrations that could represent the diverse nature of the program. In addition to program diversity, we were interested in the experiences of CODO and non-CODO students. CODO refers to students who changed their degree option and investigating CODOs provided a unique window into the rationales of students who started in a different major than MDE or IDES.

Three recruitment strategies were used. The first strategy involved an email blast to the target population of IDES and MDE students. Following the email blast, we issued a callout in the professional preparation course for sophomore engineering students and contacted the program director for additional participants. As students responded to the various callouts, we assessed the variations desired in the sample and sought out additional participants as needed. The final list of participants is provided in Table 1. We asked each student to give a pseudonym to protect their anonymity. As indicated in Table 1, the sample demonstrated comparable distributions of CODO and non-CODO students and a diversity of specializations and interest areas. While we made exhaustive efforts to recruit sophomores, all the students in the sample are upper-level students (juniors and seniors), which is a limitation of the pilot study. 
Table 1. Participant characteristics

\begin{tabular}{|c|c|c|c|c|}
\hline Participant & CODO & Classification & Specialization & Diversity of interests/Goals \\
\hline Rooskie & $\mathrm{Y}$ & Senior & $\begin{array}{c}\text { Veterinarian Health } \\
\text { Engineer }\end{array}$ & $\begin{array}{c}\text { Veterinarian, Spanish, Global } \\
\text { Engineering Studies }\end{array}$ \\
\hline Doc Martin & $\mathrm{N}$ & Senior & $\begin{array}{c}\text { Diversity and } \\
\text { Inclusion } \\
\text { Engineering }\end{array}$ & Diversity and Inclusion \\
\hline John & $\mathrm{N}$ & Senior & $\begin{array}{c}\text { Computer } \\
\text { Information } \\
\text { Technology, } \\
\text { Management, and } \\
\text { Electrical } \\
\text { Engineering }\end{array}$ & Economics and art \\
\hline Ch-Reader & $\mathrm{Y}$ & Senior & $\begin{array}{c}\text { Engineering } \\
\text { Management } \\
\text { Robotics and } \\
\text { Mechanical Design }\end{array}$ & Aerospace and Business \\
\hline Sarah & $\mathrm{N}$ & Senior & $\begin{array}{c}\text { Atmosphere Science } \\
\text { Engineer }\end{array}$ & Wobotic Surgery \\
\hline Jack Wells & $\mathrm{Y}$ & Senior & $\begin{array}{c}\text { General Engineering } \\
\text { Whangergy }\end{array}$ & $\begin{array}{c}\text { Psychology, human factors, } \\
\text { managent }\end{array}$ \\
\hline
\end{tabular}

\section{Procedure}

In prior work [14], we characterized the landscape of programs with an interdisciplinary, integrated, and multidisciplinary nature. This allowed us to identify a list of programs websites for students to explore and use for comparative purposes. Once students agreed to participate in the study, they were asked to 1) explore the program website, 2) identify an additional program website from a pre-defined list, and 3) respond to four debrief questions. The focus of this work is to understand what information shapes students interests to pursue an interdisciplinary engineering education. We used techniques for conducting usability studies such as tracking the user's experience and think-aloud protocol to elicit student rationales for choosing the program. For this study, we asked each student to navigate the program website to begin to probe their reason for pursuing an interdisciplinary engineering education.

The semi-structured interview protocol was designed to allow the students to openly explore the program website to identify information that is significant for their decision making. The students were encouraged to think-aloud as they navigated the website to communicate their expectations (i.e., what are you looking for), real-time experiences (i.e., what did you see), and suggestions to improve the website content or design (i.e., how could the desired information or design be enhanced). We used Silverback, a software program for usability studies, to record navigation behavior and think-aloud audio as students navigated program websites [15]. When we asked the 
students to identify an institution from a predefined list of interdisciplinary or multidisciplinary engineering programs and search for the program, we observed four patterns. These patterns include:

1) Not able to locate the program using a search engine $(n=1)$

2) The program was only designated for graduate students $(n=3)$

3) The website provided limited information for the user $(n=1)$

4) The institution's characterization of an interdisciplinary or multidisciplinary engineering program were exclusive to non-engineering disciplines $(n=2)$

Because other program websites did not provide rich data for this study, the key insights presented in this paper focus only on student experiences with their current program. After completing the website review, students were asked to respond to four debrief questions. The purpose of these questions was to elicit what stood out to the student, what influenced their decision to pursue an interdisciplinary engineering education program, share their short and long-term goals, and how the program website aligned with their academic and professional interests.

\section{Key Insights}

This paper describes preliminary findings regarding the user experiences of seven engineering students while navigating the program website, as well as their rationale for selecting a multidisciplinary engineering or interdisciplinary engineering studies program. Historically, student enrollment in the multidisciplinary engineering and interdisciplinary engineering studies program are significantly smaller than other professional engineering programs at this institution. We do not aim to generalize the experiences of these students; instead, we are interested in uncovering the experiences of engineering students who do not identify with traditional engineering disciplines. Slaton and Pawley (2018) discuss how these "small-n" studies "shed light on individual and collective experiences that are far more layered than conventional engineering educational research methodologies [16, pp. 137-138]." In addition to shedding light on inclusive engineering education research methodologies, this work expands the current understandings of an unconventional engineering path.

The usability interviews reveal three key insights: 1) the first source of information students identify are the program requirements, especially when timing is of concern, 2) IDES and MDE students value community, inclusion, and conscientiousness in engineering and 3) IDES and MDE students' value structured autonomy.

\section{First Stop: Clear program requirements and students sharing real-time experiences}

When students were asked to navigate the program website, five of the students navigated to the program requirements icon or text link located in the left margin of the webpage, one student navigated to a concentration, and one student navigated to the student blog section. Four of the students had changed their degree (CODO at various points in their undergraduate program, therefore when looking for a program that accommodated their diverse interests, they shared that they were interested in a program that would not extend their intention to graduate in four academic years, not exceed their financial obligation for a higher education, and some students wanted a program that was ABET accredited. Six students described their affinity with the highly visual 
degree requirements flowchart outlining the program expectations and course options for each academic term. In addition to the program requirements, some students navigated to the student blogs "call to action" link to read about the experiences of current and previous students. For example, Rooskie described how "I'm like understanding what the classes were required, understanding how students use it and like what's going on in it right now.... I'm just trying to get your handle on like what is this engineering thing in general? So, I would probably be looking for what students are doing with it. Um, so this student blog thing here." This finding highlights the value of using visual representations to outline the experience in the program, as well as sharing real-time experiences of current students.

\section{A culture of Inclusion}

Each student described how either the MDE and IDES program afforded them the autonomy and flexibility to explore their diverse interests. One student described how the MDE program opened "a door where I felt like there was no door open before." John always knew that he wanted to be an engineer; however, before joining the MDE program, he was unsure if it were possible with a traditional engineering path. Similar to John, Doc Martin had a strong interest in engineering; however, pre-college engineering experiences of discrimination of her gender and sexuality sparked her interests in becoming an engineer to "breakdown those barriers with the different privileges that have been afforded to me" through her future role in industry. Both of these examples demonstrate how the program is inclusive with regard to affording students an unconventional path to becoming an engineer and inclusive for students who value social justice as an essential aspect of engineering education. This finding highlights how the multidisciplinary engineering program and interdisciplinary engineering studies program promotes a culture of inclusion of ideas and fosters a sense of belonging for students' that are different.

\section{Flexibility to Tailor a Plan}

A common narrative among the seven students is a realization that their respective interests do not align with the identity of a traditional engineering program. Six students described how they could not explore their non-engineering interest in a traditional engineering program, due to the structural limitations associated with the historical disciplinary bounds in the program. For example, one student who is interested in non-invasive robotic surgery design described how the mechanical engineering plan of study was “... very restricted about all the courses and the coursework that I had to do, and I think I had like five classes of choice." Four students described how they were interested in the self-design plan of study based on their unique interests, and three students described how the website was useful for learning about the program in a general sense but that it was essential to speak with the academic leadership team to get a more detailed or personalized view. Sarah shared how her interaction with the leadership team helped her solidify her enrollment in the program. Jack Wells described how after speaking with his mechanical engineering advisor, he worked with the academic advisor to identify "... credits that would transfer," so he could "tailor" his plan of study in alignment with his diverse interests inside and outside of engineering. This finding highlights the magnitude of human resources that are necessary to accommodate diverse academic needs. 


\section{Future Work}

This work begins to provide an in-depth understanding of the intrinsic motivations of students who pursue an engineering program that supports their diverse interests. While these experiences are from a retrospective perspective, they offer insight into how a program website can be enhanced to help prospective students navigate their academic path. Ultimately, all of the students were interested in identifying the program or degree requirements to visualize a clear blueprint of what they are expected to complete in the program. In addition to the academic blueprint, they are interested in learning about the experiences of current students with student blogs or vlogs. These are the essential sources of information that help students gain interests in the program; however, it is clear how the website is an initial point of contact, while the academic leadership team seals the deal.

The students in our study were attracted to the interdisciplinary engineering studies and multidisciplinary engineering program, due to its structure that permits students to design their plan of study according to their interests. This program attribute was one of the key reasons students selected the IDES or MDE program, in addition to the students who changed their academic major, due to their unsatisfactory experience in their traditional engineering discipline. Another program attribute that attracted students include the inclusive environment that supports individual differences and fosters community through professional organizations and comfort zones that give students a sense of belonging. These students were seeking a program that allowed them to explore their interests, in addition to engineering. More importantly, the students acknowledge that this type of education does not fit any student. Instead, they discussed the importance of students with a passion for a cause. This work begins to explore how multidisciplinary engineering and interdisciplinary engineering studies programs support students with diverse interests. Our future work includes using these insights to provide recommendations to the program director, as well as use the preliminary findings to investigate the multidisciplinary engineering program as a hybrid space to understand their identity development and belonging in engineering. 


\section{References}

[1] Accreditation Board for Engineering and Technology. Criteria for Accrediting Engineering Programs for implementation in the 2019-2020 accreditation cycle. 2018.

[2] National Academy of Engineering. The Engineer of 2020: Visions of Engineering in the New Century. Washington. 2004.

[3] C. E. Foor, S. E. Walden, and D. A. Trytten, "II Wish that I Belonged More in this Whole Engineering Group:' Achieving Individual Diversity,” J. Eng. Educ., vol. 96, no. 2, pp. 103-115, 2007.

[4] B. A. Danielak, A. Gupta, and A. Elby, "Marginalized Identities of Sense-Makers: Reframing Engineering Student Retention,” J. Eng. Educ., vol. 103, no. 1, pp. 8-44, 2014.

[5] H. M. Matusovich, R. A. Streveler, and R. L. Miller, "Why Do Students Choose Engineering? A Qualitative, Longitudinal Investigation of Students' Motivational Values," J. Eng. Educ., vol. 99, no. 4, pp. 289-303, 2010.

[6] I. B. Ngambeki, Finding a home in engineering: Examining students' choice of engineering discipline. Theses and Dissertations Available from ProQuest, 9, 1-143. 2012.

[7] H. E. Rodríguez-Simmonds, J. D. Ortega-Alvarez, S. Z. Atiq, \& S. R. Hoffmann, identifying sources of information that students use in deciding which engineering major to pursue. ASEE Annual Conference and Exposition. 2015.

[8] C. E. Brawner, M. M. Camacho, S. M. Lord, R. A. Long, \& A. W. Ohland, Women in industrial engineering: Stereotypes, persistence, and perspectives. Journal of Engineering Education, 101(2), 288-318. 2012.

[9] D. B. Knight, L. R. Lattuca, E. W. Kimball, \& R. D. Reason, Understanding Interdisciplinarity: Curricular and Organizational Features of Undergraduate Interdisciplinary Programs. Innovative Higher Education, 38(2), 143-158. 2013.

[10] H. B. Carlone, \& A. Johnson, Understanding the science experiences of successful women of color: Science identity as an analytic lens. Journal of Research in Science Teaching, 44(8), 1187-1218. 2007.

[11] A. Godwin, G. Potvin, \& Z. Hazari, Identity, Critical Agency, and Engineering: An Affective Model for Predicting Engineering as A Career Choice. J. Eng. Educ., vol. 105, no. 2, pp. 312-340. 2016.

[12] B. Benedict, D. Verdín, R. A. Baker, A. Godwin, and T. Milton, "Uncovering Latent Diversity: Steps Towards Understanding 'What Counts' and 'Who Belongs' in Engineering Culture," in 2018 ASEE Annual Conference \& Exposition, 2018.

[13] Donna Riley, Rigor/Us: Building Boundaries and Disciplining Diversity with Standards of Merit, Engineering Studies, 9:3, 249-265, 2017.

[14] R. S. Waller, D. R., Benedict, B, Aleong, R. J., Adams, "Surveying and Characterizing the Landscape of Interdisciplinary Experiences," Poster presented at Illinois-Indiana ASEE Section Conference, 2018.

[15] Clearleft Ltd., "Silverback 3," [Online]. Available: https://silverbackapp.com/. [Accessed 2018].

[16] Amy E. Slaton \& Alice L. Pawley, The Power and Politics of Engineering Education Research Design: Saving the 'Small N', Engineering Studies, 10:2-3, 133-157. 2018. 